\title{
To Evaluate Povidone-iodine Effect On Post Appendectomy Surgical Site Infection
}

\author{
Rizwanullah Junaid Bhanbhro, Khalil Ahmed Almani, Sadia Kazi, Navaid Kazi, Sumayya Kazi
}

Objective: Evaluating the effects of Povidone- Iodine against the surgical site infection in post- appendectomy wound infection.

Study design: Randomized clinical trial

Place and duration: Department of Surgery, Isra University Hospital Hyderabad from January 2016 to December 2017.

Subjects and Methods: Patients of acute appendicitis with classical clinical presentation were selected according to inclusion and exclusion criteria. 60 patients were those in which wound was irrigated with $1 \%$ povidone-iodine solution versus 60 patients in whom wound not irrigated with it before skin closure. Data was analyzed on SPSS 22.0 using Student t-test and Chi- square test respectively. Data was analyzed at $95 \%$ confidence interval $(\mathrm{P}=0.05)$. $\mathrm{P}$-value of $=0.05$ was taken statistically.

Results: Mean \pm SD age of control and cases was noted as $22.5 \pm 7.5$ and $23.5 \pm 6.5$ years respectively $(\mathrm{P}=0.86)$. Male and female population in control and cases were noted as $45(75 \%)$ and $15(25 \%) \& 47(78.33 \%)$ and $13(21.66 \%)$ respectively $(\mathrm{P}>0.05)$. Grade 4 pus discharging wound infection was noted in $3.33 \%$ in control compared to $1.66 \%$ in cases $(\mathrm{P}=0.87)$. Normal wound healing ( grad 0$)$ was noted in $37(61.6 \%)$ and $43(71.6 \%)$ of control and cases respectively. In control grade $1-4$ lesions were noted in $38.4 \%$ compared to $28.4 \%$ in cases $(\mathrm{P}<0.05)$.

Conclusion: Simple irrigation of appendectomy wound with 1\% povidone- iodine significantly prevents against the surgical site infection and pus formation.

Key words: Surgical site infection, Povidone-Iodine, Appendectomy

\section{INTRODUCTION:}

Surgical site infection (SSI) is one of the commonest post operative complication of appendectomy. ${ }^{1,2}$ A prevalence of $18-20 \%$ of SSI has been reported despite prophylactic use of antibiotics and improved sterilization techniques. ${ }^{3,4}$ Povidone-iodine is amongst the widely used antiseptic for wound sterilization. Povidone-Iodine is composed of $1 \%$ iodine, iodide and polyvinyl pyrrolidone dissolved in sterilized water. Povidone- iodine shows bactericidal activity against wide range bacteria and other micro organisms. Its effect begins within thirty seconds of application and lasts for as long as 14 hours. ${ }^{4,5}$ The efficacy of Povidone-Iodine

Rizwanullah Junaid Bhanbhro

I Associate Professor, Department of Surgery

Isra University Hospital, Hyderabad

Email: 321junaid@gmail.com

Khalil Ahmed Almani

Assistant Professor

I Isra University Hospital, Hyderabad

I Sadia Kazi

I Assistant Professor, Department of Pharmacology

Isra University, Hyderabad

I Navaid Kazi

Professor, Department of Physiology

Isra University, Hyderabad

I

Sumayya Kazi

Assistant Professor, Department of Biochemistry

I Isra University, Hyderabad

I Received: 29-03-2018

I Accepted: 07-09-2018

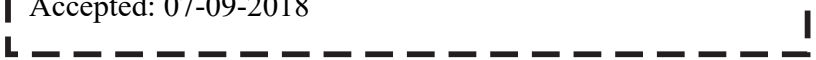

solution is well established on wounds with intact surrounding skin, ${ }^{\mathbf{5 , 6}}$ but studies studied its use as prophylactic agent against bacteria in SSI are limited. ${ }^{7,8}$ This might be due to safety concerns in open wounds. ${ }^{9}$ The bacterial killing activity of Povidone-Iodine increases with more degree of dilutions. For example $0.1-1 \%$ dilute Povidone-Iodine solutions are reported more bactericidal than $10 \%$ concentrated Povidone-Iodine solutions. ${ }^{4,5}$ Povidone-Iodine is neither cytotoxic nor retards the wound healing at high concentration. It is approved by the Food and Drug Administration (FDA) as bactericidal for superficial and acute wounds for short term duration. ${ }^{9-11}$ As the appendectomy is termed as contaminated surgery and oftently performed by young surgeons, ${ }^{1}$ hence there are more chances of surgical site infection (SSI). SSI creates discomfort to patients, increases duration of morbidity and increases economical loss and discourages the surgeons. Post operative hospital stay and cost of procedure is increased by the SSI. ${ }^{11,12}$ As the appendectomy is a widely used surgical procedure particularly in the youngsters, hence the SSI is problematic. The present study was designed to compare the efficacy of Povidone- iodine solution against the frequency of superficial surgical site infections in post - appendectomy patients at our tertiary care hospital. Comparison was made between those in which wound was irrigated with $1 \%$ povidoneiodine solution versus those in whom wound was not irrigated with it before skin closure. The study was of clinical importance as if $1 \%$ povidone-iodine decreases the SSI, then it will be a simple and inexpensive remedy for prevention of surgical site infection. 
To Evaluate Povidone-iodine Effect On Post Appendectomy Surgical Site Infection

\section{SUBJECTS AND METHODS:}

The present randomized controlled trial was conducted at the Department of Surgery, Isra University Hospital Hyderabad. Isra University Hospital is a tertiary care hospital that caters hundreds of thousands patients each year. Surgical wards are one of the busiest units of the hospital. The study was conducted over duration from January 2016 to December 2017. Ethical approval was taken from the Institute's ethical committee. Patients of acute appendicitis with classical clinical presentation of pain in right iliac fossa; nausea, vomiting, and fever were included. 60 patients were those in which wound was irrigated with $1 \%$ povidone-iodine solution versus 60 patients in whom wound not irrigated with it before skin closure. Age 10- 25 years, volunteer subjects with clinical diagnosis of acute appendicitis were included. Appendectomy was performed in the emergency surgical operation theater. Exclusion criteria were defined as; appendicular abscess, perforated appendix, inflammatory bowel disease, and systemic disease such as the diabetes mellitus were excluded. Malnourished patients were also excluded. Appendectomy was performed by standard surgical procedure under general anesthesia. Grid iron incision was used for the open appendectomy. All of patients received prophylaxis of cephalosporin antibiotic (1 gram) intravenously for prevention of infection. Patients were categorized into control and cases by random selection. After surgical procedure, the wound was irrigated with $1 \%$ povidone-iodine solution (cases) versus those in whom wound not irrigated with it (control) before skin closure. In cases, the subcutaneous tissue was irrigated with $1 \%$ diluted povidone- iodine (4- $5 \mathrm{ml}$ ), while controls were not. Povidoneiodine solution was taken into $5 \mathrm{ml}$ disposable syringe (BD, USA), and was sprayed into the subcutaneous wound. Povidone- iodine was applied and exposed for 2- 3 minutes. In control patients, the wound was not irrigated. Skin was closed by surgical sutures (continuous sub cuticle) in both control and cases. Dressing was applied to the wound site and tethered with paper plaster. Post operatively, 2 grams of cephalosporins were given intravenously for infection control in both groups. Surgical procedure was performed by consultant surgeon in the operation theater. Wound site was observed for the surgical site infection (SSI), at the time of discharge, and on successive follow up visits in the outpatient clinic till $30^{\text {th }}$ post operative day. Surgical site wound was classified as per Southampton Wound Grading System. ${ }^{12}$ All volunteers were asked to sign the consent form. Form was signed either by the patient itself or by his legal heirs. Signing of consent form was mandatory for inclusion in research protocol. Patient's biodata, diagnosis, vitals, surgical procedure, antibiotic prophylaxis, discharge and follow up and surgical site infections were noted in a pre- structured proforma. Confidentiality of patients data was strictly maintained in accordance to the "Helsinki`s declaration". Continuous and categorical variables were analyzed on SPSS 22.0 (Statistical Package for Social Science, Inc. Chicago, IL, USA) using Student t-test and Chi- square test respectively. Data was analyzed at $95 \%$ confidence interval $(\mathrm{P}=0.05)$. $\mathrm{P}$-value of $=0.05$ was taken statistically.

\section{RESULTS:}

Mean \pm SD age of control and cases was noted as $22.5 \pm$ 7.5 and $23.5 \pm 6.5$ years respectively $(\mathrm{P}=0.86)$. Subjects in control and cases were matched for age, body weight and gender (table 1 and Fig1). Systolic and Diastolic BP and Random blood glucose (RBG) results are presented in table 1. Gender distribution is presented in fig 1 . Male and female population in control and cases were noted as $45(75 \%)$ and $15(25 \%) \& 47(78.33 \%)$ and $13(21.66 \%)$ respectively (P $>0.05$ ). Wound grading of control and cases according to Southampton grading $0-4$ is presented in table 2 . Grade 0 , 1 and 3 were found less in cases $(\mathrm{P}<0.05)$ compared to control subjects. Grade 4 pus discharging wound infection was noted in $3.33 \%$ in control compared to $1.66 \%$ in cases $(\mathrm{P}=0.87)$. Fig 2 shows the distributio of Southampton wound grading of study subejcts. Normal wound healing (grad 0) was noted in $37(61.6 \%)$ and $43(71.6 \%)$ of control and cases respectively. In control grade 1-4 lesions were noted in $38.4 \%$ compared to $28.4 \%$ in cases $(\mathrm{P}<0.05)$.

\begin{tabular}{|l|c|c|c|}
\hline & Control & Cases & P-value \\
\hline & Mean \pm SD & Mean \pm SD & \\
\hline Age (years) & $22.5 \pm 7.5$ & $23.5 \pm 6.5$ & 0.86 \\
\hline Body weight (kg) & $54.7 \pm 12.5$ & $57.9 \pm 10.5$ & 0.79 \\
\hline Systolic BP (mmHg) & $117.9 \pm 11.04$ & $115.5 \pm 10.8$ & 0.91 \\
\hline Diastolic BP(mmHg) & $69.15 \pm 10.0$ & $71.5 \pm 9.5$ & 0.45 \\
\hline RBG (mg/dl) & $137.8 \pm 15.8$ & $128.53 \pm 56.47$ & 0.74 \\
\hline
\end{tabular}

Table 1. Demographic characteristics of control and cases $(n=120)$

\begin{tabular}{|l|c|c|c|}
\hline & Control & Cases & P-value \\
\hline & No. (\%) & No. (\%) & \\
\hline Grade 0-(healing normal) & $37(61.6 \%)$ & $43(71.6 \%)$ & 0.0001 \\
\hline Grade 1-(Mild bruising) & $9(15.0 \%)$ & $7(11.6 \%)$ & 0.003 \\
\hline Grade 2-(Erythema) & $7(11.6 \%)$ & $6(10.0 \%)$ & 0.931 \\
\hline Grade 3-(Serous discharge) & $5(8.3 \%)$ & $3(5.0 \%)$ & 0.049 \\
\hline Grade 4-(Pus discharge) & $2(3.33 \%)$ & $1(1.66 \%)$ & 0.87 \\
\hline
\end{tabular}

Table 2. Wound grading in control and cases $(n=120)$

\section{DISCUSSION:}

In present randomized clinical trial, the efficacy of $1 \%$ Povidone- iodine against surgical site infection (SSI) was noted in post- appendectomy patients. The presents study shows wound grade 0,1 and 3 were found less in cases (P $<0.05$ ) compared to control subjects. In present study, normal wound healing (Soutampton grade 0 ) was noted in $37(61.6 \%)$ and $43(71.6 \%)$ of control and cases respectively that was insignificant $(\mathrm{P}>0.05)$, but the severity of infection was 




Fig 1. Bar graph showing gender distribution of study subejcts

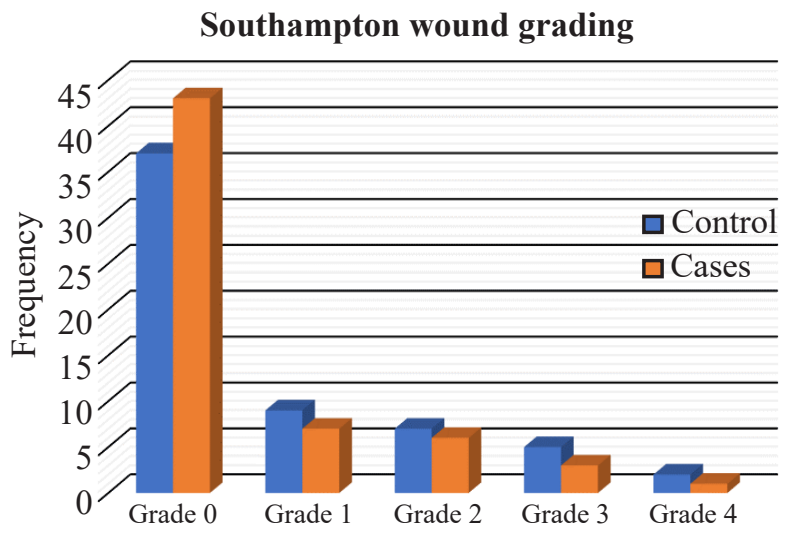

Fig 2. Southampton wound grading of study subejcts

significantly less in $1 \%$ Povidone- Iodine treated wounds. Grade 1-4 lesions were noted in 38.4\% controls compared to $28.4 \%$ in cases $(\mathrm{P}<0.05)$ that was statistically significant. In present study, the grade 4 pus discharging wound infection was noted in $3.33 \%$ in control compared to $1.66 \%$ in cases $(\mathrm{P}=0.87)$. This is in agreement with previous studies ${ }^{13-14}$ which has reported frequency of wound infection of 2.1 to $20 \%$ in post- appendectomy subjects. However, a recent study ${ }^{12}$ has reported a frequency of $15.1 \%$ of wound infection which is high and is not in keeping with present and previous studies as above. ${ }^{3,13,14}$ A previous study from Lahore, reported $13.1 \% \mathrm{SSI}$ in open appendectomy cases, ${ }^{\mathbf{1 5}}$ that is also high compared to $3.33 \%$ in control and $1.66 \%$ in cases. Previous studies $^{16,17}$ reported SSI in $5 \%$ and $6.4 \%$ of open appendectomy respectively. The frequency rates of both studies are consistent with the present study. Another study ${ }^{3}$ reported high frequency of $18 \%$ of SSI among pediatric populace; this is in contrast to low frequency of SSI noted in the present study. These controversies are because of different study populations as pediatric versus adults, different severity of appendicitis cases, postgraduate versus consultant surgeons and post operative care differs from hospital to hospital. In our tertiary care, the post operative care is par excellence hence the overall SSI was noted low. Another reason of varied presentation of post appendectomy SSI is inconsistent and non standardized definitions of surgical site wound infection. In above studies ${ }^{3,13,14}$ the criteria of wound infection were not clearly mentioned. Another reason matters is the comparison of SSI of laparoscopic versus open appendicectomy that is incomparable. ${ }^{18}$ In present study, surgical wound infection was in accordance to Southampton wound grading system. According to Southampton wound grading, the normal wound healing (grad 0) was noted in $37(61.6 \%)$ and $43(71.6 \%)$ of control and cases respectively. In control grade 1-4 lesions were noted in $38.4 \%$ compared to $28.4 \%$ in cases $(\mathrm{P}<0.05)$. These findings are consistent to previous studies. ${ }^{17,18}$ Purulent discharge from the wound of post appendectomy is the hallmark of ongoing infective process of SSI. In present study, the grade 4 pus discharging wound infection was noted in $3.33 \%$ in control compared to $1.66 \%$ in cases $(\mathrm{P}=$ $0.87)$. Pus discharge indicates persistent bacterial proliferation at the wound site with release of inflammatory mediators and toxins by the microbial pathogens. ${ }^{5}$ Pus is a sure sign of SSI. Application of antiseptic agent such as $1 \%$ PovidoneIodine inhibits the bacterial growth and halts the process of SSI and formation of pus in the wound cavity. ${ }^{\mathbf{5 9}}$ In present study, $1 \%$ of Povidone- Iodine significantly reduced the surgical site infection and pus formation. A previous study ${ }^{19}$ reported efficacy of Povidone- Iodine solution against SSI, as they reported infection rate of $15.1 \%$ in control compared to $2.9 \%$ in cases. This frequency is comparable to $3.33 \%$ SSI in cases noted in the present study. ${ }^{19}$ The findings of present study are also supported by previous study ${ }^{20}$ as they reported demonstrated the Povidone-iodine application was effective in reducing the SSI. The only limitation of present study is the small sample size. However, results are worth to report as simple application of Povidone- Iodine is useful against the surgical site infection.

\section{CONCLUSION:}

The present study concludes that simply the irrigation of appendectomy wound with $1 \%$ povidone- iodine significantly prevents against the surgical site infection and pus formation. Future studies with large sample size are recommended for further clarification of efficacy of Povidone- iodine against the surgical site infections.

\section{REFERENCES:}

1. Parthiban N, Harish M. A study on microbiology culture of acute appendicectomy specimen and its correlation with wound infection. Int Surg J 2017;4 :2212-5.

2. Jan Y. Comparison of postoperative wound infection in open versus laparoscopic appendectomy. Rawal Med J 2014; 39:557.

3. Khan MN, Fayyad T, Cecil TD, Moran BJ. Laparoscopic versus Open Appendicectomy: the risk of postoperative infectious complications. J Soc Laparos Surg 2007; 11:363-7. 
To Evaluate Povidone-iodine Effect On Post Appendectomy Surgical Site Infection

4. Mughal SA, Soomro S. Acute appendicitis in children. J Surg Pak 2007; 12:123-5.

5. Perveen S, Sarwar G, Saeed N, Channa GA. Laparoscopic versus open appendicectomy as an elective procedure. Med Channel 2007; 13:18-20.

6. Selvaggi G, Monstrey S, Vanlanduyt K, Hamdi M, Blondeel $P$. The role of iodine in antisepsis and wound management: a reappraisal. Acta Chir Belg 2003; 103:241-7.

7. Nishimura C. Comparison of the antimicrobial efficacy of povidone-iodine, povidone-iodine-ethanol and chlorhexidine gluconate-ethanol surgical scrubs. Dermatology 2006; 212:215.

8. Cheng MT, Chang MC, Wang ST, Yu WK, Liu CL, Chen TH. Efficacy of dilute betadine solution irrigation in the prevention of post operative infection of spinal surgery. Spine 2005; 30:1689-93.

9. Harihara Y, Konishi T, Kobayashi H, Furushima K, Ito K, Noie T, et al. Effect of applying povidone-iodine just before skin closure. Dermatology 2006; 212:53-7.

10. Drousou A, Falabella A, Kirsner RS. Antiseptics on wounds: an area of controversy. Wounds 2003; 15:149-66.

11. Chang FY, Chang MC, Wang ST, Yu WK, Liu CL, Chen TH. Can povidone-iodine solution be used safely in a spinal surgery? Eur Spine J 2006; 15:1005-14.

12. Iqbal M, Jawaid M, Qureshi A, Iqbal S. Effect of povidoneiodine irrigation on post appendectomy wound infection: randomized control trial. J Postgrad Med Inst 2015; 29(3): $160-4$.
13. Arshad M, Aziz LA, Qasim M, Talpur KA. Early appendicectomy in appendicular mass: a Liaquat University hospital experience. J Ayub Med Coll Abottabad 2008; 20:70-2.

14. Kouwenhoven EA, Repelaer van Driel OJ, van Erp WF. Fear for the intra-abdominal abscess after laparoscopic appendectomy: not realistic. Surg Endosc 2005; 19:923-36.

15. Shah SA. Laparoscopic appendicectomy versus conventional open appendicectomy: A study at Lahore General Hospital. Esculapio J Services Inst Med Sci 2008; 3:21-24.

16. Ahmad N, Abid KJ, Khan AZ, Shah STA. Acute Appendicitis-Incidence of Negative Appendicectomies. Ann King Edward Med Coll 2002; 8:32-4.

17. Chaudhary IA, Samiullah MAA, Afridi Z, Bano A. Is it necessary to invaginate the stump after appendicectomy? Pak J Med Sci 2005; 21:35-8.

18. Koederitz NM, Neely DE, Plager DA, Boehmer B, Ofner S, Sprunger DT et al. Postoperative povidone-iodine prophylaxis in strabismus surgery. J AAPOS 2008; 12:396-400.

19. Pattana-arun J, Wolff BG. Benefits of povidone-iodine solution in colorectal operations: science or legend. Dis Colon Rectum 2008; 51:966-71.

20. Shindo K, Funai S, Kuroda K, Wakano T, Nishimura K. Clinical study on the antiseptic effect of povidone-iodine solution for the surgical field of digestive tract operations. Dermatology 2002; 204:47-51 